\title{
Allergic reaction to long - term Benzathine penicillin injection for secondary prevention of acute rheumatic fever and recommendations for skin testing.
}

Regmi P. R, Upadhyaya $A B$

National Academy of Medical Sciences, Bir hospital

Medicare National Hospital and research centre

\section{Address for Correspondence:}

Dr. Prakash Raj Regmi,

National Academy of Medical sciences

Bir Hospital, Kathmandu, Nepal,

Email: prregmi@wlink.com.np

\section{Abstract \\ Background}

Rheumatic Fever (RF) causes $25-40 \%$ of all cardio vascular disease in developing countries. Long term benzathine penicillin injection is being used for secondary prophylaxis of RF / RHD. Although allergic reaction to penicillin is rare skin testing is performed routinely before each and every penicillin injection delivery in most of the hospitals in Nepal.

\section{Objectives}

Objectives of this study was to evaluate safety of long term benzathine penicillin injection and establish recommendations for penicillin skin testing.

\section{Methods}

Data from the registers of National RF/RHD prevention and control programme from 32 hospitals of Nepal were collected and analyzed in a retrospective study.

\section{Results}

65 patients (1.4\%) among 77300 injections of benzathine penicillin given to 4712 patients, had allergic reactions. 5 had anaphylaxis, an incidence of $0.1 \%(0.7 / 10000$ injections), 60 had minor allergy, an incidence of $1.3 \%$.

\section{Conclusions}

Life-threatening allergic reactions are very rare in patients on long-term intramuscular benzathine penicillin for secondary prevention of RF. With these rare complications, regular skin test before each and every benzathine penicillin injection delivery has no significant role. Nevertheless Skin testing is recommended before $1^{\text {st }}$ injection and patients having different batch number and or brand name.

\section{Key Words}

Rheumatic Fever, Rheumatic Heart Disease, Inj. benzathine penicillin, Allergic reactions, Secondary prophylaxis 


\section{Introduction}

Rheumatic Fever (RF) causes $25-40 \%$ of all cardio vascular disease in developing countries ${ }^{1}$. Disability and death from Rheumatic Heart Disease (RHD) are mainly caused by recurrent attacks of $\mathrm{RF}^{2}$. The efficacy of antibiotic prophylaxis to prevent recurrences of RF has been known for over 70 years ${ }^{3,4}$. Because of the impact of this disease on public health, and the proven efficacy of antibiotic prophylaxis, the World Health Organization has helped to establish programmes for prevention of RF in developing countries ${ }^{5}$.

RF and RHD are common cardiac problem in Nepal with prevalence rate of $1.2 / 1000$ children aged $5-16$ years $^{6}$. Long term benzathine penicillin injection is being used for secondary prophylaxis of RF / RHD.

Although allergic reaction to penicillin is rare skin testing is performed routinely before each and every penicillin injection delivery in most of the hospitals in Nepal. There are no published guidelines and recommendations for skin testing before penicillin injection delivery. Ministry of Health and Population of Nepal has been implementing a national programme on RF/RHD prevention and control with the technical support of Nepal heart foundation since last 4 years.

Objectives of this study was to evaluate safety of long term benzathine penicillin injection and establish recommendations for penicillin skin testing

\section{Methods}

Data from the registers of National RF/RHD prevention and control programme from 32 hospitals of Nepal were collected and analyzed in a retrospective study. This enrolled 4712 RF/RHD patients from June 2007 to Feb 2010 who received 3 weekly benzathine penicillin injection for Secondary prevention of RF.

Analysis of the patients with allergic reactions to inj. Benzathine penicillin was done.

\section{Results}

77300 injections of benzathine penicillin were delivered to 4712 patients during the study period. Among them 2172 (46.1\%) were males and 2540 (53.9\%) were females, 1728 (36.7\%) were under 18 years and 2994 (63.3\%) were above 18years. 665(14.1\%) were RF and 4141 (85.9\%) were RHD.

65 patients (1.4\%) had allergic reactions. 5 had anaphylaxis, an incidence of $0.1 \%$ (0.7/10000 injections), 60 had minor allergy, an incidence of $1.3 \%$. Among them 10 patients had minor allergy while receiving new batch of benzathine penicillin (incidence of $0.2 \%$ ) and 18 patients had minor allergy with new brand of injection penicillin ( change from Penidure LA to Pencom ) an incidence of $0.4 \%$. There were 8 vasovagal reactions $(0.16 \%)$ ( Table 2 ). Among them 6 were with severe RHD. No death was reported. All allergic reactions occurred in age group $>18$ Years.

\begin{tabular}{|c|c|c|c|c|}
\hline \multicolumn{5}{|c|}{ Table 1} \\
\hline \multicolumn{5}{|c|}{ Total patients - 4712} \\
\hline Sex: & Male & $2172(46.1 \%)$ & Female & $2540(53.9 \%)$ \\
\hline Age: & $<18 y r s$ & $1728(36.7 \%)$ & $>18 y r s$ & $2994(63.3 \%)$ \\
\hline Diagnosis: & RF & $665(14.1 \%)$ & RHD & $4047(85.9 \%)$ \\
\hline
\end{tabular}

\begin{tabular}{|l|l|}
\hline & Table 2 \\
\hline Total patients & $: \mathbf{4 7 1 2}$ \\
\hline Reaction to Penicillin & $: 65(1.4 \%)$ \\
\hline Major & $: 5(0.1 \%),(0.7 / 10000$ injections) \\
\hline Minor & $\begin{array}{l}: 60(1.3 \%),(8.4 / 10000 \\
\text { injections) }\end{array}$ \\
\hline Vaso-vagal syncope & $: 8(0.16 \%)$ \\
\hline
\end{tabular}

\section{Discussion}

The $1.4 \%$ incidence of allergic reaction observed among patients with RF/RHD in our study differs from $3.2 \%$ incidence reported by International Rheumatic Fever Study Group $^{7,8}$ and also incidence of $2.24 \%$ reported in patients who received short term treatment with benzathine penicillin for sexually transmitted disease ${ }^{9}$.

Anaphylaxis is the most worrying allergic reaction to penicillin. The reported incidence of serious reactions among patients without a history of rheumatic fever or of penicillin allergy ranges from 1-4/10000 treatment course $^{10}$. In our study the 4 episodes of anaphylaxis among 4712 RF/RHD patients who received 77300 injections represent a frequency of $0.7 / 10000$ injections. This shows the frequency of serious allergic reactions to penicillin to be rare. The risk of such allergic reaction in age group under 12 years is reported very low ${ }^{11}$.

Although skin tests for penicillin allergy are not recommended for patients without a history of such allergic reactions, it is possible that selective skin test with penicillin might further reduce the already low risk of a fatal reaction in patients with severe RHD. Patients with a positive skin test could receive an alternate prophylactic drug as Erythromycin.

It is necessary to note the batch number and brand name of the injection benzathine penicillin in the developing countries as ours because of the possible differences in quality of the drug with different manufacturers and batches. 


\section{Nepalese Heart Journal}

\section{Conclusions}

Life-threatening allergic reactions are very rare in patients on long-term intramuscular benzathine penicillin for secondary prevention of RF. Minor reactions to penicillin may also occur with change in batch number and brand. It is not beneficial to perform skin test before each and every benzathine penicillin injection delivery.

Skin testing is recommended before $1^{\text {st }}$ injection and patients having different batch number and or brand name. Consent taking is recommended with all patients before $1^{\text {st }}$ benzathine penicillin injection delivery for legal safety of health personal delivering the injection.

\section{References:}

1. Agarwal BL. Rheumatic fever and rheumatic heart disease in developing countries. A monograph. New Delhi. Arnold Publishers, 1988

2. Taranta A, Markowitz M. Rheumatic fever. A monograph $2^{\text {nd }}$ edition, London: Kluwer,1989

3. Thomos CB, France R. A preliminary report of the prophylactic use of sulfonamide in patients susceptible to rheumatic fever. Bulletin Johns Hopkins Hosp.1939; 54; 67-77

4. Coburn AF, Moore LV. The prophylactic use of sulfonamide in streptococcal respiratory infection with special reference to rheumatic fever. J. Clin Invest 1939: 18: 147-155

5. Strasser T, Dongdon N, EL Kholy AM, Gharagozloo R, Report of a WHO international cooperative project. Bulletin WHO 1981; 59; $285-94$

6. Regmi PR, Pandey MR. Prevalence of RF and RHD in school children of Kathmandu city. Indian heart journal 1997,49,518520

7. International rheumatic fever study group. Allergic reactions to long-term benzathine penicillin prophylaxis for rheumatic fever. Lancet 1991. 337, 1308-1310

8. Markowitz M, Lue HC. Allergic reaction in rheumatic fever patients on long term benzathine penicillin $\mathrm{G}$; the role of skin testing for skin allergy. Paediatrics, 1996. 97(s): 981-983

9. Weiss ME, Adkinson NF. Immediate hypersensitivity reactions to penicillin and related antibiotics. Clin Allergy 1988;18;51540

10. Enffmeyer JE. Penicillin Allergy. Clin Rev Allergy 1986;4;171-86

11. Sullivan TJ. Pathogenesis and management of allergic reactions to penicillin and other beta-lactam antibiotics. Pediatr Infect Dis 1982;1;344-50 